\title{
Efficacy of ProEx C in Detecting Cervical Squamous Epithelial Lesions: A Cross-sectional Study
}

\author{
Ashwini Nayak U ${ }^{1} \odot$, Vijayshree Muthukumar ${ }^{2}$, HS Sridhar $^{3}$, Vivaan Dutt $^{4}$, Madhu P Raj ${ }^{5}$
}

\begin{abstract}
Objectives: To determine the diagnostic value of ProEx C in the detection of cervical squamous epithelial lesions.

Materials and methods: A cross-sectional study was conducted on 60 cataloged cervical biopsy specimens. The specimens were received from incident cases for routine histopathological evaluation in MS Ramaiah Hospital. Immunohistochemical examination was performed on paraffin biopsy blocks of the specimen for nuclear and cytosolic staining with ProEx C. From the data, the proportion of positive staining cells and the average intensity of staining were assessed.

Results: As per this study, the sensitivity and specificity of ProEx C were found to be 95 and $83 \%$, respectively.

Conclusion: ProEx $\mathrm{C}$ is an ascertained highly sensitive and specific marker. This will help to overcome the drawbacks of basic screening methods in terms of inter- and intra-observer variations and false-positive and false-negative values, and either replace or complement the less economical human papillomavirus (HPV) DNA testing in the triage for developing nations.

Clinical significance: The use of ProEx C as an immunohistochemical marker is a highly reliable indicator of not only the presence of cervical squamous epithelial lesions but also the grade of the lesion. With high positive and negative predictive values for dysplasia and invasive carcinomas as well, ProEx $C$ serves as an excellent diagnostic tool for cervical intraepithelial lesions.

Keywords: DNA topoisomerase II, Immunohistochemistry, MCM2-7 helicase, Uterine cervical neoplasms.

Journal of South Asian Federation of Obstetrics and Gynaecology (2020): 10.5005/jp-journals-10006-1844
\end{abstract}

\section{INTRODUCTION}

Cervical cancer is globally the second most prevalent cancer among women and ranks third among cancer-causing deaths in India. According to WHO, India contributes to one-fifth of the world's burden with an incidence rate of 30.7 per 1,00,000 women and 72,600 annual deaths. ${ }^{1}$ This is due to a large population of women in the low socioeconomic strata who lack access to screening and health services and inadequate awareness about the risk factors of cervical cancer. This predisposes the women to a high risk of mortality or leaves them with embarrassing symptoms, such as foul odored vaginal discharge, vaginal fistulae, and discomfort during intercourse, and abnormal bleeding. ${ }^{2}$

However, cervical carcinoma can be prevented by efficient screening, early detection, and prompt treatment as infection with high-risk human papillomavirus (HPV) has been established almost exclusively as the cause. The long latency period between initial HPV exposure and development of cervical cancer up to several years gives ample scope for intervention and prevention. ${ }^{3}$

Several preventive strategies have been explored and a standardized triage has been established. The introduction of Pap smear in the 1950s dramatically decreased cervical cancer incidence and mortality rates by more than $60 \%$ in the West. ${ }^{4}$

Yet Pap smear is a rather crude screening method whose efficiency depends on its frequency of repetition. Inter- and intraobserver variations and false-positive (5-70\%) and false-negative rates (20-30\%) besides having certain inconclusive results hamper this, which is a psychological stress on the patient. Technical developments of this test, such as the liquid-based cytology have not shown significant improvement in sensitivity or specificity for detection of high-grade cervical intraepithelial neoplasia. The sensitivity of a single Pap smear is reported to be between 60 and
${ }^{1}$ Department of Obstetrics and Gynaecology, MS Ramaiah Medical College, Bengaluru, Karnataka, India

${ }^{2}$ Department of Pediatrics, Indira Gandhi Institute of Child Health, Bengaluru, Karnataka, India

${ }^{3}$ Department of Pathology, MS Ramaiah Medical College, Bengaluru, Karnataka, India

${ }^{4}$ Department of General Surgery, VIMS, Bellari, Karnataka, India

${ }^{5}$ IVth MBBS, MS Ramaiah Medical College, Bengaluru, Karnataka, India

Corresponding Author: Ashwini Nayak U, Department of Obstetrics and Gynaecology, MS Ramaiah Medical College, Bengaluru, Karnataka, India, Phone: +91 9845070730, e-mail: uashwininayak@gmail.com

How to cite this article: Nayak AU, MuthukumarV, Sridhar HS, et al. Efficacy of ProEx C in Detecting Cervical Squamous Epithelial Lesions: A Crosssectional Study. J South Asian Feder Obst Gynae 2020;12(6):383-386.

Source of support: ICMR (Indian Council of Medical Research) and MERT (Medical Education and Research Trust, Bengaluru)

Conflict of interest: None

$80 \%$ and specificity around $80 \%$. Since doing random cervical biopsies is discouraged, a colposcopy is warranted by the WHO. ${ }^{4}$

The most commonly used test to detect the HPV DNA in the cervical tissue is RT-PCR. ${ }^{5}$ Though RT-CPR can detect the presence of HPV DNA, it is incapable of neither distinguishing acute and chronic infections, nor concluding the presence of neoplastic changes with the detection of the viral DNA. Besides, the test is less economical and requires the equipment to run a $P C R$, thus not suited for a developing nation.

Biomarkers indicating the initiation of neoplastic transformation in HPV-infected epithelial cells are currently in the focus of cancer

(0) Jaypee Brothers Medical Publishers. 2020 Open Access This article is distributed under the terms of the Creative Commons Attribution 4.0 International License (https://creativecommons.org/licenses/by-nc/4.0/), which permits unrestricted use, distribution, and non-commercial reproduction in any medium, provided you give appropriate credit to the original author(s) and the source, provide a link to the Creative Commons license, and indicate if changes were made. The Creative Commons Public Domain Dedication waiver (http://creativecommons.org/publicdomain/zero/1.0/) applies to the data made available in this article, unless otherwise stated. 
prevention research. Cell-cycle proteins can serve as novel markers on histological specimens to improve the identification of women with ambiguous results that require treatment. ${ }^{5} \mathrm{~A}$ new marker, ProEx C (a mixture of two antibodies against mini-chromosome maintenance protein 2 and DNA topoisomerase Ila), has shown to have the highest specificity among the markers, up to $74.5 \%{ }^{6}$

In HPV-infected squamous cells, binding of E6 and E7 viral on co-proteins to $\mathrm{p} 53$ and RB genes leads to a deregulation of the cell cycle and abnormal expression of cell-cycle-associated proteins. Two newer biomarkers, mini-chromosome maintenance protein 2 and DNA topoisomerase lla, play a significant role in the regulation of DNA replication during S-phase and are overexpressed when S-phase cellcycle induction is aberrant. ProEx $\mathrm{C}$ is a cocktail of two monoclonal antibodies that target the expression of these two proteins. ${ }^{7}$

Recent studies have validated the accuracy of ProEx $C$ in liquid-based cytology as an axillary test; however, literature on its application on tissue sections and Pap smears remains limited. ${ }^{8}$

\section{Materials and Methods}

The cross-sectional study was conducted in MS Ramaiah Teaching Hospital, Bengaluru, in the Department of Pathology and the Department of Obstetrics and Gynecology. For the study sample, 60 cervical biopsy specimens received from incident cases for routine histopathological evaluation from the Department of Obstetrics and Gynecology were utilized.

The study has been approved by the Ethical Review Board, MS Ramaiah Medical College and Hospitals, and an ethical clearance certificate was issued as a testament to the same. Inclusion criteria were as follows:

- Cervical biopsy specimens were received from incident cases for routine histopathological evaluation.

- Biopsies from hysterectomy done for gynecological conditions.

Exclusion criteria were as follows:

- Inadequate tissue biopsy.

- Ulcerated and necrotic tissue.

- Biopsies of secondary carcinomas of the cervix.

For retrospective cervical biopsy cases, the histopathology reports, slides, and paraffin blocks were retrieved from the archives. Sections of $4 \mu \mathrm{m}$ thickness were cut from the paraffin block of cervical biopsy tissue and taken on a glass slide coated with polyL-lysine for immunohistochemistry (IHC) to detect ProEx C. The technique employed for $\mathrm{IHC}$ included antigen retrieval in citrate buffer in a microwave oven, blocking endogenous peroxidase with $3 \%$ hydrogen peroxide, incubating with primary mouse monoclonal antibody against ProEx C (Clone EPR4120 and EP1102Y) linking with rabbit anti-mouse secondary antibody (BioGenex, USA), enzyme labeling with streptavidin-horseradish peroxidase (BioGenex, USA), developing chromogen with diaminobenzidine (DAB), and counterstaining with hematoxylin. Positive and negative controls were run with each batch of slides.

The H\&E-stained slides were studied for the histopathological changes and categorizing the cervical lesion. The immunostained slides were examined for nuclear staining with ProEx C. In each case, the proportion of positive staining cells (expressed as percentage) and the average intensity of staining (expressed as $0,1+, 2+$, or 3+) were evaluated. The percentage of ProEx C positive squamous cells was recorded as basal (stained nuclei less than $25 \%$, occupying the lower quarter of cervical epithelium), lower half (25-50\% stained positive), lower three-fourth (50-75\% stained positive), and fullthickness (75-100\% of nuclei stained positive).

For statistical analysis, the proportion of the patients having a diagnosis of precancerous and cervical carcinoma with ProEx C was estimated with a $95 \%$ confidence interval. ProEx C Validation for the diagnosis of pre-cancerous lesions was done using sensitivity, specificity, positive predictive value (PPV), and negative predictive value (NPV).

\section{Results}

Demographic characteristics: A total of 60 biopsies of confirmed cases of cervical intraepithelial lesions and invasive carcinoma of the cervix in the general population were included in this study. The mean age among the 60 samples was 47 years varying between 20 and 80 years.

Positive staining for ProEx C was exclusively nuclear, uniformly strong, and band-like involving different levels of the epithelium. The percentage distribution was recorded as basal (stained nuclei less than $25 \%$ of lower quarter of cervical epithelium), lower half (25-50\% of nuclear positivity or involving less than half the thickness of the epithelium), lower threequarters (50-75\% nuclei staining or staining involving less than a three-quarter thickness of the epithelium), and full-thickness (75-100\% nuclear positivity).

Of the 12 cases of non-specific cervicitis, 10 showed negative staining as expected for ProEx C, while one case showed low-grade dysplasia with ProEx $C$ and one showed high-grade dysplasia. Of the 12 cases of low-grade dysplasia, six cases showed CIN I with both the markers, two showed negative staining with ProEx $C_{1}$ and four cases were shown to be high-grade dysplasia. Of the 24 cases of high-grade dysplasia (CIN II and CIN III), 21 cases showed high-grade dysplasia as expected while three cases were shown to be low-grade dysplasia. All 12 cases of invasive carcinoma were confirmed by this particular marker. Table 1 depicts the pattern of expression of ProEx $C$ in cervical lesions in the cervical biopsy specimen. This indicates that the expression of ProEx C significantly correlates with the degree of dysplasia.

ProEx C had a higher sensitivity $(95.83 \%)$ than specificity (83.33\%) for detecting the spectrum of cervical lesions. The positive and negative predictive values were 95.83 and $83.33 \%$, respectively.

With reference to high-grade dysplasia, that is, CIN II and CIN III, ProEx C had a sensitivity of $78.26 \%$ and specificity of $86.48 \%$.

Table 1: Pattern of expression of ProEx C in cervical lesions among cervical biopsy specimen

\begin{tabular}{|c|c|c|c|c|c|}
\hline $\begin{array}{l}\text { Consensus } \\
\text { diagnosis }\end{array}$ & $\begin{array}{l}\text { Negative } \\
\text { (\%) }\end{array}$ & $\begin{array}{l}0-25 \\
(\%)\end{array}$ & $\begin{array}{l}25-50 \\
(\%)\end{array}$ & $\begin{array}{l}50-75 \\
(\%)\end{array}$ & $\begin{array}{l}75-100 \\
(\%)\end{array}$ \\
\hline $\begin{array}{l}\text { Low-grade } \\
\text { dysplasia }\end{array}$ & $2 / 12$ & $6 / 12$ & $2 / 12$ & $1 / 12$ & $1 / 12$ \\
\hline (CIN I) & (16.67\%) & $(50 \%)$ & (16.67\%) & (8.34\%) & (8.34\%) \\
\hline $\begin{array}{l}\text { High-grade } \\
\text { dysplasia }\end{array}$ & $0 / 12$ & $2 / 12$ & $4 / 12$ & $6 / 12$ & $0 / 12$ \\
\hline (CIN II) & $(0 \%)$ & (16.67\%) & (33.34\%) & $(50 \%)$ & $(0 \%)$ \\
\hline $\begin{array}{l}\text { High-grade } \\
\text { dysplasia }\end{array}$ & $0 / 12$ & $0 / 12$ & $3 / 12$ & $4 / 12$ & $5 / 12$ \\
\hline (CIN III) & $(0 \%)$ & (16.67\%) & (75\%) & (33.34\%) & (41.67\%) \\
\hline \multirow{2}{*}{$\begin{array}{l}\text { Invasive } \\
\text { carcinoma }\end{array}$} & $0 / 12$ & $0 / 12$ & $0 / 12$ & $0 / 12$ & $12 / 12$ \\
\hline & $(0 \%)$ & (0\%) & (0\%) & (0\%) & $(100 \%)$ \\
\hline
\end{tabular}


Table 2: Comparison of test characteristics of ProEx $C$ in all cervical lesions among various studies

\begin{tabular}{llllll}
\hline $\begin{array}{l}\text { Overall } \\
\text { performance }\end{array}$ & Current study & $\begin{array}{l}\text { Pinto } \\
\text { et al. }\end{array}$ & $\begin{array}{l}\text { Badr } \\
\text { et al. }\end{array}$ & $\begin{array}{l}\text { Kelly } \\
\text { et al. }{ }^{11}\end{array}$ & $\begin{array}{l}\text { Guo } \\
\text { et al. }\end{array}$ \\
\hline Sensitivity & $95.83 \%$ & $87 \%$ & $75 \%$ & $83.5 \%$ & $74 \%$ \\
Specificity & $83.33 \%$ & $71 \%$ & $97 \%$ & $71.7 \%$ & $90 \%$ \\
PPV & $95.83 \%$ & - & $98 \%$ & $44.6 \%$ & $98 \%$ \\
NPV & $83.33 \%$ & - & $71 \%$ & $94.8 \%$ & $80 \%$ \\
\hline
\end{tabular}

Table 3: Comparison of test characteristics of ProEx $C$ in the detection of high-grade dysplasia in cervical biopsy specimen

\begin{tabular}{llllll}
\hline $\begin{array}{l}\text { High-grade } \\
\text { dysplasia }\end{array}$ & $\begin{array}{l}\text { Current } \\
\text { study }\end{array}$ & $\begin{array}{l}\text { Siddiqui } \\
\text { et al. }^{6}\end{array}$ & $\begin{array}{l}\text { Badr } \\
\text { et al. }^{10}\end{array}$ & \multicolumn{2}{c}{ Guo et al. $^{5}$} \\
\hline (CIN II/III) & CINII/III & CINII/III & CINII/III & CIN II & CIN III \\
Sensitivity & $78.26 \%$ & $98.04 \%$ & $92 \%$ & $67 \%$ & $84 \%$ \\
Specificity & $86.48 \%$ & $74.50 \%$ & $80 \%$ & $85 \%$ & $79 \%$ \\
PPV & $78.26 \%$ & $56 \%$ & $74 \%$ & $90 \%$ & $76 \%$ \\
NPV & $86.48 \%$ & $82 \%$ & $94 \%$ & $60 \%$ & $86 \%$ \\
\hline
\end{tabular}

ProEx C had a high sensitivity (86.95\%) and specificity (86.48\%) for high-grade dysplasia. In a study conducted by Tambouret, the sensitivity and specificity of ProEx $\mathrm{C}$ as a marker for high-grade dysplasia were evaluated at 81 and $82 \%$, respectively. ${ }^{9}$ The positive and negative predictive values were 80 and $91.42 \%$, respectively. Studies conducted by Guo et al., ${ }^{5}$ Pinto et al., ${ }^{8}$ Badr et al., ${ }^{10}$ and Kelly et al. ${ }^{11}$ show comparable test characteristics of ProEx $C$ in the detection of all cervical lesions. These variables have been tabulated and depicted in Table 2. Table 3 shows the test characteristics of high-grade dysplasia in the current study and studies conducted by Guo et al., ${ }^{5}$ Siddiqui et al., ${ }^{6}$ and Badr et al..$^{10}$

\section{Discussion}

The current research aims to assess the performance of ProEx $C$ in the detection of pre-cancerous cervical lesions. Using IHC on paraffin-fixed cervical biopsies, the expression of the marker was analyzed and the results of the study will be compared to other similar studies to draw conclusions.

In India, it is reported that the average age for invasive cervical cancer is 55-59 years and precancerous lesions tend to occur 10-15 years earlier. 3 The average age for precancerous lesions was 43 with a range of 20-60 in this study.

With reference to the interpretation of the immunohistochemical slides, three parameters were taken into consideration.

- The percentage nuclear for ProEx C.

- The intensity of staining.

- The pattern of staining of the cells. To make a diagnosis of non-specific cervicitis with ProEx C, it was negative staining or staining of less than $10 \%$ of the basal cells.

- To make a diagnosis of low-grade dysplasia (CIN I) with ProEx C, it was nuclear staining in $25 \%$ of the squamous cells in the lower half of the epithelium. Figure 1 shows an immunohistochemical stained slide showing in more than a quarter of the contiguous squamous cells showing nuclear and cytoplasmic positivity.

- To make a diagnosis of high-grade dysplasia (CIN II/III) with ProEx C, it was nuclear staining in $50-75 \%$ of the squamous cells in

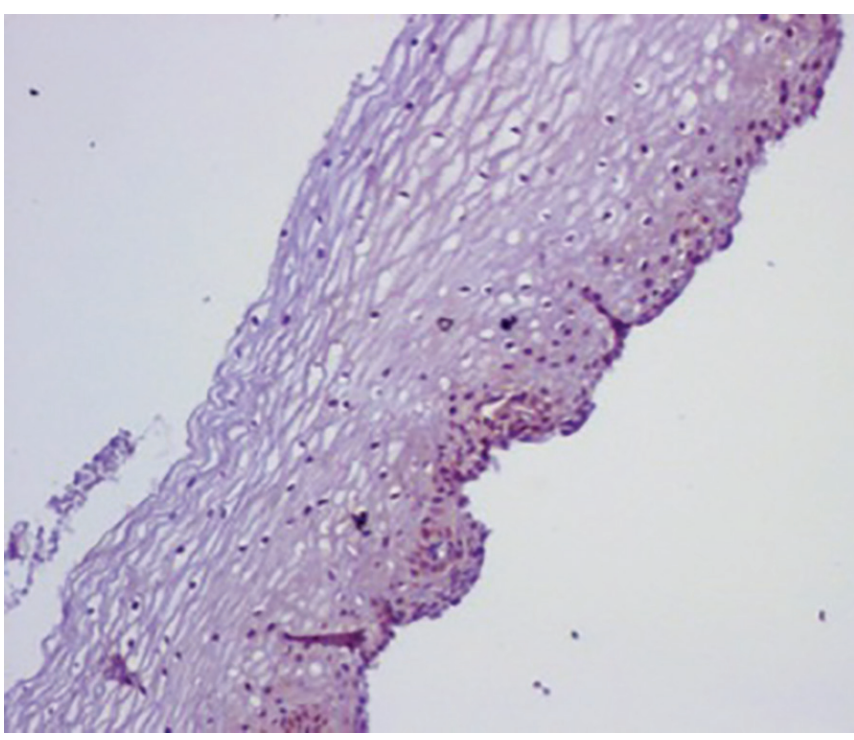

Fig. 1: ProEx C staining of cervical biopsy specimen: the following slide shows nuclear and cytoplasmic positivity in $>25 \%$ contiguous squamous cells (spotty) (×100): low-grade dysplasia CIN I

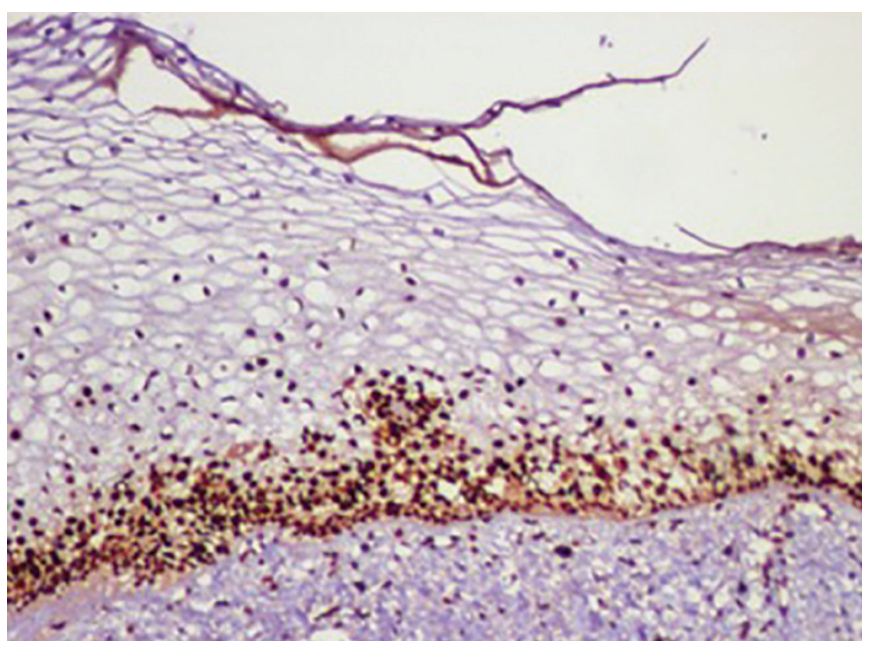

Fig. 2: ProEx C staining of cervical biopsy specimen: the following slide shows nuclear and cytoplasmic positivity in $>50 \%$ contiguous squamous cells (spotty) (×200): high-grade dysplasia CIN II

the lower three-fourth of the epithelium for CIN II and nuclear staining in $75-100 \%$ of squamous cells in the full thickness of the epithelium for CIN III. Figures 2 and 3 show nuclear and cytoplasmic positivity in more than 50 and $90 \%$, respectively. However, stroma not being infiltrated in Figure 3 confirms grade 3 of cervical intraepithelial neoplasia.

- To make a diagnosis of invasive carcinoma with ProEx C, it was nuclear staining in $100 \%$ of squamous cells in the full thickness of the epithelium plus a marked stromal invasion. The same is depicted in Figure 4, showing nuclear and cytoplasmic positivity in full-thickness and invasion of stroma.

\section{Ethics Approval}

The ethical approval has been duly obtained by the Institutional Review Board, Ramaiah Medical College and Hospitals. The proposal 


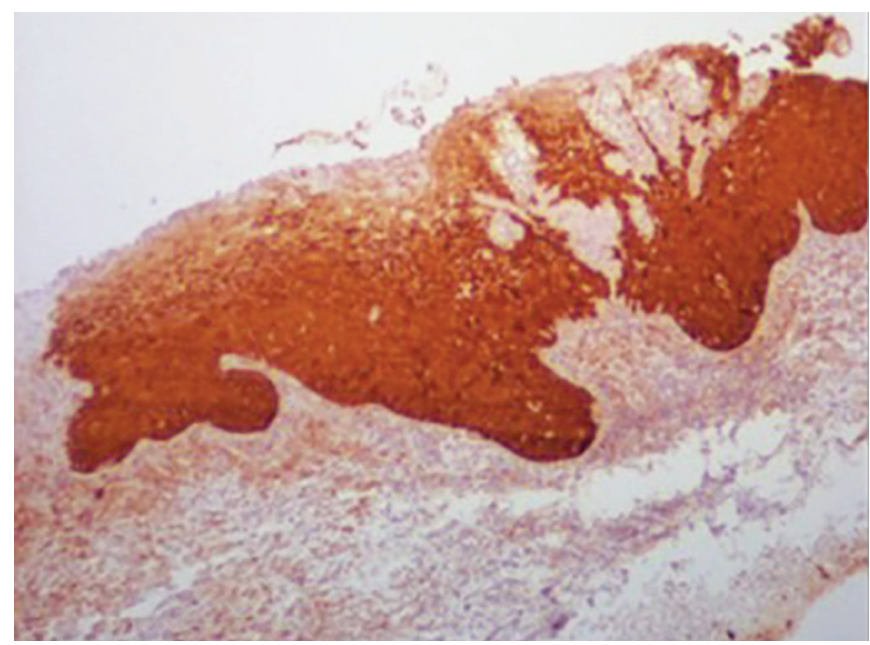

Fig. 3: ProEx C staining of cervical biopsy specimen: the following slide shows nuclear and cytoplasmic positivity in $>90 \%$ contiguous squamous cells (band-like) (×100): high-grade dysplasia CIN III

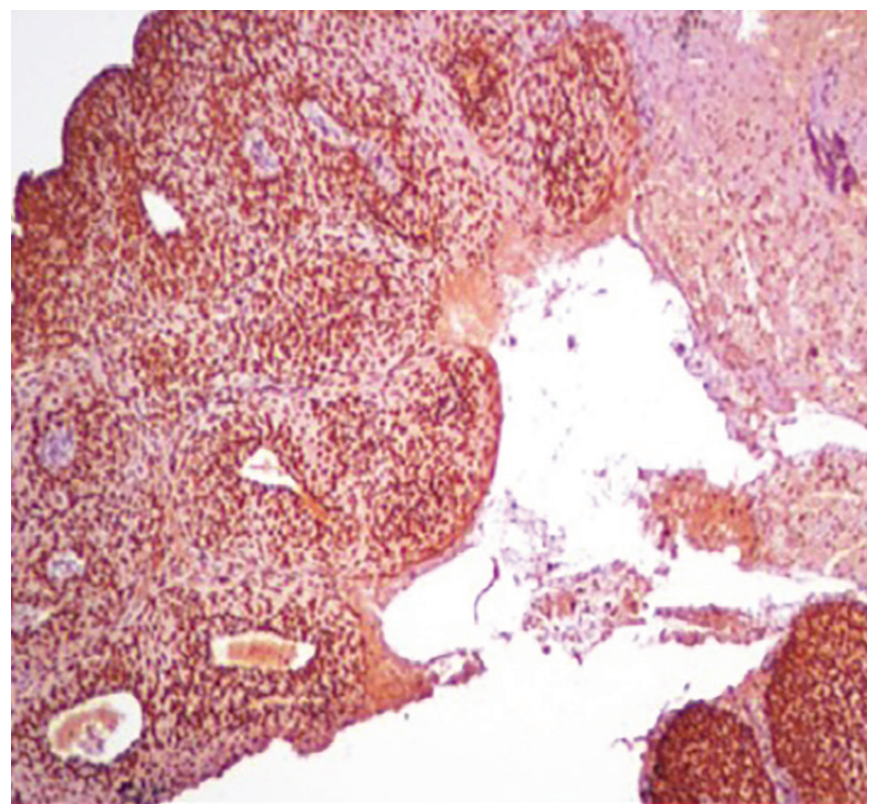

Fig. 4: ProEx C staining of cervical biopsy specimen: the following slide shows positivity in $>90 \%$ contiguous squamous cells with invasion in stroma (diffuse) $(\times 100)$ : squamous cell carcinoma

for the same was submitted in the year 2014. The ethical clearance certificate was issued after thorough scrutiny.

\section{Conclusion}

This study looks at the usefulness of establishing ProEx $C$ as a routine marker in the diagnosis of dysplasia and cervical squamous epithelial lesions. The sensitivity and specificity being high tell us that this particular marker is capable of not only diagnosing the lesions but also tells us that with high specificity it can rule out cervical lesions in cases where the patient is free of disease. However, Pap smear being the gold standard as of now, this leaves us with the conclusion that ProEx C can complement Pap smears adequately and effectively if not replace it. More importantly, this establishes the efficacy of ProEx $C$ such that in lower socioeconomic countries, this can be a better alternative to HPV DNA testing in terms of economic feasibility while being highly sensitive and specific. ProEx C can complement HPV DNA testing if not for complete replacement.

\section{Acknowledgment}

Heartfelt acknowledgment to MERT (Medical Education and Research Trust), Bengaluru, for extending financial support.

\section{OrCID}

Ashwini Nayak U ๑ https://orcid.org/0000-0002-6259-2086

\section{References}

1. WHO Bull. Control of cancer of the cervix, a WHO meeting. Bull World Health Organ 1986;64(4):607-618.

2. Kurkure AP, Yeole BB. Social inequalities in cancer with special reference to South Asian countries. Asian Pac J Cancer Prev 2006;7(1):36-40.

3. Sreedevi A, Javed R, Dinesh A. Epidemiology of cervical cancer with special focus on India. Int J Womens Health 2015;7:405-414. DOI:10.2147/IJWH.S50001.

4. Safaeian M, Solomon D, Castle PE. Cervical cancer preventioncervical screening: science in evolution. Obstet Gynecol Clin North Am 2007;34(4):739-760, ix. DOl:10.1016/j.ogc.2007.09.004.

5. Guo M, Baruch AC, Silva EG, et al. Efficacy of p16 and ProExC immunostaining in the detection of high-grade cervical intraepithelial neoplasia and cervical carcinoma. Am J Clin Pathol 2011;135(2):212220. DOI: 10.1309/AJCP1LLX8QMDXHHO.

6. Siddiqui MT, Cohen C, Nassar A. Detecting high-grade cervical disease on ASC-H cytology: role of BD ProEx C and digene hybrid capture II HPV DNA testing. Am J Clin Pathol 2008;130(5):765-770. DOI: 10.1309/ AJCPWW6V2KGXODUI.

7. Beccati MD, Buriani C, Pedriali M, et al. Quantitative detection of molecular markers ProEx C (minichromosome maintenance protein 2 and topoisomerase Ila) and MIB-1 in liquid-based cervical squamous cell cytology. Cancer 2008;114(3):196-203. DOI: 10.1002/ cncr.23496.

8. Pinto AP, Schlecht NF, Woo TYC, et al. Biomarker (ProEx C, p16(INK4A), and $\mathrm{MiB}-1$ ) distinction of high-grade squamous intraepithelial lesion from its mimics. Mod Pathol 2008;21(9):1067-1074. DOI: 10.1038/ modpathol.2008.101.

9. Tambouret RH. Valeur diagnostique du ProEx ${ }^{\mathrm{TM}} \mathrm{C}$ en cytopathologie gynécologique. Ann Pathol 2008;28(1):S92-S93. DOI: 10.1016/j. annpat.2008.09.030.

10. Badr RE, Walts AE, Chung F, et al. BD ProEx C: a sensitive and specific marker of HPV-associated squamous lesions of the cervix. Am J Surg Pathol 2008;32(6):899-906. DOI: 10.1097/ PAS.0b013e31815bbb69.

11. Kelly D, Kincaid E, Fansler Z, et al. Detection of cervical high-grade squamous intraepithelial lesions from cytologic samples using a novel immunocytochemical assay (ProEx C). Cancer 2006;108(6):494500. DOI: 10.1002/cncr.22288. 